\title{
Community Translation: Translation as a social activity and its possible consequences in the advent of Web 2.0 and beyond
}

\author{
Minako O’Hagan \\ Dublin City University
}

This introduction to the 10th issue of Linguistica Antverpiensia New Series - Themes in translation Studies (LANS-TTS) begins by discussing the central concept of community translation, highlighting its terminological ambiguity. This is in part due to the already well-established field of community interpreting where the term is often used to mean the written translation of public information for immigrants. It is also an indication of the terminological instability typical of an emerging paradigm. For example, community translation is used more or less synonymously with such terms as translation crowdsourcing, user-generated translation and collaborative translation. The meaning of the term as we discuss in this issue can be best specified when the concept is anchored in the context of Web 2.0 (second generation web-technologies). This in turn acknowledges its intrinsic tie to online communities and directs us to new dynamics resulting from general Internet users acting as translators. While participants in community translation are not necessarily all unpaid, untrained volunteers community translation is used by some organisations as a mechanism to obtain free translations by going outside the professional translation sphere. To this end the ethical question of profitmaking enterprises accessing free labour on the pretext of openness and sharing remains. That said, the author believes community translation is far more than a dilettante, anti-professional movement. Building on the emerging picture from the contributions in this volume, the author suggests some of the future directions that research on community translation might take, emphasising the need to reflect on the current translation practices and be open to the new developments and opportunities arising from the free and social Internet.

\section{Background}

Focusing on increasingly visible and somewhat controversial translation practices typically performed by unspecified individuals on the Internet, this tenth edition of Linguistica Antverpiensia New Series - Themes in Translation Studies explores key issues arising from the emerging translation phenomenon of community translation.

Due partly to the existing concept and practice of community interpreting which has become well established in Translation Studies (TS) 
the term community translation is not entirely transparent. As commented by Pym (2011), the term's usage by some authors especially in Australia and the US is closely associated with community interpreting, referring mainly to the written translation of public information for an immigrant population. Over the last decade, community interpreting has become more and more professionalised but it still frequently involves "untrained individuals" and is often associated with "amateurism and ad hoc solutions" (Wadensjö, 2009, p. 43). Perhaps it is in the latter sense of involvement of non-professionals that community translation and community interpreting may point to some conceptual overlap. However, at least according to our usage in this volume, the key difference is that unlike community interpreting, community translation is tied to the online community particularly in the specific context of Web 2.0. As such it signifies specific translation practices that are unfolding on the Internet as the central foci. Nevertheless, given the inherent difficulty in defining community due to its multiplicity as more recently highlighted by Internet researchers (Kendall, 2011), community translation calls for further explanation.

First used at the O'Reilly and Associates conference in 2004, the slogan Web 2.0 has become an influential concept (Barry, 2008), if at times somewhat over-hyped. The second generation web technologies have become strongly identified with such key words as user-generated content and social networking. However, Nancy Baym (2011) reminds us that usergenerated content is in fact not new as "all of the content on the Internet was generated by people, for people" from the start (p.384). According to Baym (2011), the development of "professionally provided content" for profit is newly brought about by Web 2.0 as an alternative to free usergenerated content which dominated the Internet until 1994. She highlights how the free user-generated content is now often destined for profit-making enterprises such as Facebook and YouTube. Furthermore, the dimension of social networking has become the most distinctive feature of Web 2.0 platforms as the "participative web" (OECD, 2007) where people exchange ideas, collaborate and share with others their own user-generated content, thus leading to a web of social interactions that generate business.

It is this broad technological milieu in which community translation is couched with the implied meaning of a community of Internet users. For example, Google valued YouTube at $\$ 1.65$ billion at the time of its acquisition, not for the company of 67 employees but "for the community the people who use it" that are in the multimillions (Howe, 2008, p. 109). In this way the concept of community in the era of Web 2.0 has acquired a specific meaning, which warrants the term community translation despite the problems mentioned at the beginning. When Facebook filed a patent for its purpose-built translation application in August 2009 at the US Patent $\&$ Trademark Office, the invention was named Community Translation On A Social Network and described as: " "embodiments of the invention provide techniques for translating text in a social network". Not surprisingly, the 
Facebook example best illustrates how community translation is tightly woven into social networking. As mentioned by several contributors in this volume, the Facebook user translation initiatives became the most publicised early example of community translation, where a group of selfselected Internet users translate fragments of text to be used on the Facebook website in different language versions. These translators are mostly already Facebook members familiar with the environment; if not, volunteers need to be registered with Facebook in order to use its own purpose-built translation platform. The proposed translations are in turn voted on by other Facebook users. Translators who contribute well in terms of quantity and quality appear on the leader board. Added to the social networking flavour are discussions in which such community translators often passionately engage, debating translation-related issues. As illustrated by Facebook, community translation in general incorporates social dimensions where the participants interact, for example, in deciding the quality of a translation (Jiménez-Crespo in this volume). There is also clear intervention by paid professional translators in the Facebook example to maintain quality as explained by Kelly et al. in this volume.

In general, participants in community translation settings are not all untrained volunteers; professional translators also respond to a particular call which they consider worthwhile, despite a lack of remuneration. These calls for participation are usually made directly by content owners as in Facebook, making the entire exercise legally legitimate, i.e., no copyright infringement in terms of the use of the content. This contrasts with cases where individuals or groups of individuals take the liberty of carrying out their own unsolicited translation of content they themselves choose, and then share the translation on the Internet. An example of this is fan translation, notably of fansubs of Japanese anime, and now extended to a wider range of digital content, which essentially appropriates the copyrighted source material. Kageura et al. in this volume make a specific reference to copyright issues in relation to the Minna no Hon'yaku (MNH) platform, which they describe as "a translation hosting site with rich translation-aid functions". MNH only publishes materials with copyright permission, otherwise storing the materials in the users' private space while the site as a whole generally promotes Creative Commons licenses.

As is evident in the terminology usage by contributors in this volume, labels other than community translation are used more or less synonymously. A closer look indicates that terms such as translation crowdsourcing, user-generated translation (O'Hagan, 2009; Perrino, 2009) and $\mathrm{CT}^{3}$ in reference to community, crowdsourced and collaborative translation (DePalma \& Kelly, 2008) are often used with some slight differences in meaning, depending on the author. Désilets and van der Meer in this volume use collaborative translation as an umbrella term encompassing approaches such as "agile translation teamware, collaborative terminology resources, translation memory sharing, online 
translation marketplaces, post-editing by the crowd, and [...] translation crowdsourcing". From a TS perspective, Pym (2011) in turn suggests that terms such as community translation, crowdsourcing and collaborative translation "seem shot through with activist ideologies" (p. 97). Similarly Cronin (2010) finds "the subversive potential of the crowd" useful in framing crowdsourcing practices. I would argue that instances of community translation that are embedded in strict commercial contexts applied by for-profit organisations are generally devoid of such political agenda, which cannot be said of cases of fan translation and its variants. On the assumption that the key difference at stake is the remuneration, Pym (2011) recommends volunteer translation as a preferred term. Here too, as observed in contributions in this volume, a lack of monetary reward is not an essential characteristic of community translation although the act of volunteering may aptly describe the self-initiated action typical of community translation. Key common characteristics shared in the above terms highlight that it is translation performed voluntarily by Internet users and is usually produced in some form of collaboration often on specific platforms by a group of people forming an online community.

In particular, the term crowdsourcing has captured the imagination of the business world as a means of leveraging the potential capacity of the bourgeoning number of Internet users who participate en masse in various online activities in the spirit of openness, sharing and collaboration. In an analogy to the concept of outsourcing, Jeff Howe (2006) coined the term, highlighting an unknown yet potentially significant power of a crowd organically formed to perform a given task. Earlier James Surowiecki (2005) had shown how the opinions of a large number of sufficiently diverse groups of people tend to converge on the right answer, which he theorised as "the wisdom of crowds". Exploiting the potential of the Internet crowd to solve otherwise intractable problems, crowdsourcing has entered into business discourses and practices as a mechanism of distributed problem solving in the age of Web 2.0 (Tapscott \& Williams, 2006). Clay Shirky (2010), in turn, treats crowdsourcing as a manifestation of the "cognitive surplus"- the title of his book - of the vast population of Internet users who generate content in their spare time with the intention that it be shared by other users, suggesting this social dimension as a critical motivator.

Since the most high-profile early example of Facebook Translations began in the end of 2007, the crowdsourcing concept has been applied by different organisations as a means to obtain translation by reaching out to the vast resources of Internet users. However, exploitation of the Internet crowd to obtain free translations in these initiatives, in particular by 'forprofit' entities, antagonised professional translators as a development which could threaten their livelihood. When Facebook called on its users to help translate its website, various protest groups sprouted, including the 7,000strong "Leave Translation to Translators!" deriding the Facebook 
translation community as "people who think they can do it" (cited in Keegan, 2009). A subsequent similar protest by translator members of LinkedIn against what appeared to be a free ride for a for-profit company saw the formation of "Translators against Crowdsourcing for Commercial Business" (Kelly, 2009). Concerns raised by professional translators are understandable on the grounds of the likely threat to their jobs and the risk that such movements may lead to a further devaluation of what is involved in translation work (Kelly, 2009). The ethical question of profit-making enterprises exploiting free labour, no matter how willing are the volunteers, also remains. Yet the other side of the coin is that every day most remunerated translators rely on the vast amount of free user-generated content and information available on the Internet, be it glossaries of terms or technical information of all kinds in a given language. Placed in the bigger picture of the powerful trends of Internet technologies advocating openness and sharing, which is feeding through also to the design of translation tools, community translation is far too complex to be treated simply as a dilettante, anti-professional movement.

While the whole practice of translation outside the strictly professional sphere seems to have sprung up suddenly, this is not the case. Open source software under the banner of FLOSS (Free/Libre Open Source) developed a large contingency of volunteers who were often well versed in the open source domain. This group collaborated with some professional translators who were happy to be involved in these translation projects mainly without monetary compensation. Even before the FLOSS activities, fans of certain media products, as mentioned earlier, were engaged in the practice known as fan translation in order to share content with fellow fans (Díaz Cintas \& Muños Sánchez, 2007). Curiously there have been few, if any, official complaints raised by professional translators about these fan activities although there has been increasingly less tolerance demonstrated by copyright holders who had once turned a blind eye towards these mostly illegal translation activities (Leonard, 2005). The unease expressed by the professional translator community about crowdsourcing (Kelly, 2009) relates to a concern about the rise of "the cult of the amateur" (Keen, 2007). Here the term amateur has a distinctively pejorative undertone rather than the original meaning of a person who loves something.

In the meantime the trend of crowdsourcing is already clearly on the radar screen of the localisation industry, which is embracing the model (Schäler, 2008). Similarly, among those who saw scope in the emerging practice and have been working for some time to facilitate a diverse group of individuals engaged in translation were researchers with a particular interest in collaborative translation and translation technology tools (e.g., Bey et al., 2006; Désilets, 2007). At this current junction, however, for most translation professionals and scholars alike, translation practices involving the Internet crowd are still an emerging phenomenon with even 
its label yet to be agreed upon. This makes the topic ripe for discussion, especially to bridge a relative paucity of views from the Translation Studies perspective.

\section{Contributions in this volume}

This tenth edition of Linguistica Antverpiensia new Series - Themes in Translation Studies presents nine contributions, intended to provide a snapshot of different perspectives on community translation in the context of Translation Studies and from the wider circle of the industry and platform designers.

The first section, the State of Play, presents two invited papers from contributors who have been working in the field for some time. Both papers represent practically-oriented research undertaken in partnership with industry links. Alain Désilets and Jaap van der Meer first provide a detailed survey and a critical analysis of the key community translation developments to date. Among the common issues highlighted in current practices are quality control, crowd motivation and the role of professionals, which touch on themes picked up by other contributors. Grounded in current approaches, which are diverse and complex, Désilets and van der Meer attempt to capture the key essence of best practice. They aim to develop design patterns that are context-sensitive and elicit the core elements of what makes successful collaborative translation. The resultant design pattern repository, placed in a freely accessible wiki site, is intended to provide an up-to-date practical design descriptor in support of those who are implementing community translation and the initiatives in themselves demonstrate an example of the collaborative and sharing spirit. Kageura et al. in turn share a rich set of observations based on three different types of community translation platforms, which they designed and implemented. Addressing underreported issues of community translation from platform designers' perspectives, they provide a fine-grained analysis on user behaviours on each platform examining issues ranging from volunteer motivations to units of translation affected by different document types and the specific characteristics of the given translation activities. One of the platforms, Kotoba no Volunteer [Volunteers of Words], was specifically prompted by the Great East Japan Earthquake which occurred in March 2011. Its purpose is to prepare for future natural disasters by pooling useful terms and expressions which can be deployed for translating information in timely fashion by online volunteers. On the basis of the authors' experience in designing, operating and observing the different types of community translation platforms, they arrive at a big question: has translation truly gone online and collaborative involving the masses on the Internet-as much as some of us believe? It remains an open question which readers are encouraged to explore. 
The next section, Findings from Commercial Market Research Perspectives, presents research outcomes based on large-scale commercial market studies conducted by Kelly et al. who maintain that a major shift is taking place in the translation process. This involves a departure from the traditional linear model based on TEP (Translate, Edit and Publish) by a project team to a parallel translation model by a more organically formed "project community". Drawing on a large number of case studies that they have conducted the paper highlights the way in which the TEP model is giving way to a new model not solely based on collaborative translation but with multiple approaches, implementing a suite of translation technologies and in some cases employing additional in-house translators. On the basis of their studies on community translation, the authors point out that it usually exploits an already existing community as illustrated in the Facebook example (also mentioned in Kageura et al. in this volume), thus naturally rendering itself to the formation of a collaborative translation group. While the TEP model is likely to decrease in importance, the authors observe that the adoption of translation crowdsourcing by language service providers is still rare. Their observations show that organisations using the community translation model are discovering a benefit in the way it allows them "to engage meaningfully with potential customers and constituencies on a long-term basis". Having illustrated some of the deficiencies of the current translation process, the authors offer their perspective on the new community translation trend: Collaborative translation should be viewed, not as a dangerous development that threatens the profession of translation, but rather, for what it is - the market's response to specific challenges that are not being satisfactorily addressed through traditional TEP models.

The two papers presented in the third section, Ethical Implications, address ethical issues arising from community translation. By examining different types of initiatives of translation crowdsourcing, Julie McDonough Dolmaya provides a critical examination of issues that are often considered contentious by translation professionals and scholars alike, focusing on the question of remuneration, the public perception of translation and the impact on minority languages. The findings show that impacts of community translation are determined by how they are organised and communicated to the public, regardless of whether they are intended for-profit or non-profit activities. While community translation can make more visible the value of translation work to society as well as bring benefits by enhancing the presence of minority languages online, the status of translators as trained professionals may be compromised, causing devaluation of the profession overall. McDonough Dolmaya finds that the volunteers can gain satisfaction by participating in these initiatives despite not being remunerated but suggests that they are perhaps not always empowered as purported to be but may be at risk of being exploited. As such, her study leads to nuanced observations on the yet unanswered 
questions. Also addressing ethical issues, Joanna Drugan examines and compares professional codes of practice and their equivalents in community translation. She highlights some useful and original aspects of the latter codes, while clearly indicating the different priorities between the two. Her findings point to specific aspects such as "self-regulation, community policing [...] shared values rather than individual rights, and strong mentoring" as characteristics of community translation codes which at the same time seem to lack concerns about "exploitation, abuse and driving down quality standards". Drugan's suggestion that both translation groups can learn from each other is a refreshing point of view and can potentially facilitate a way forward for a profession facing a drastic change of rules affecting some fundamental and perhaps tacit work ethics.

The fourth section, Change in Norms of TQA and Language Use in Subtitling for Internet Content, focuses on the impact of community translation on translation quality assessment (TQA) norms and those of subtitle language in the advent of the gradual spread of the so-called txt lingo-also known as squeeze text-frequently used in electronically mediated communication. Taking the case of Facebook approach to TQA based on user-voting, Miguel Jiménez-Crespo argues how this "novel method", often used by community translation, embodies elements of previously proposed but largely unrealised TQA approaches in professional settings, namely "reader-based, functionalist and corpus assisted approaches". The author maintains how new online environments have made relevant and practical these earlier proposals by Translation Studies (TS) scholars that were previously believed difficult to implement. In the advent of new genre conventions such as those applicable to websites, he questions if it is "more productive to enlist large numbers of nonprofessional uses who have a deep knowledge of digital genre", as opposed to relying on professional translators who may lack such a knowledge. With the increasing translation data which organisations can now collect through community translation, Jiménez-Crespo further sees a new role of academic TS research, able to contribute to developments in the practice in the industry by providing a solid analytical basis. Also challenging existing norms and conventions, this time in the area of subtitling, Alina Secară proposes the strategic use of txt lingo in subtitles for carefully selected online materials based on initial supporting evidence from her pilot eyetracker experiments. The tests involving a set of subtitles with and without such creative spelling indicate not only no detrimental impact on viewers from the use of non-standard spelling but a benefit suggesting that the viewers were able to gain a fuller experience from the film by allowing them to fixate longer outside the subtitled area with the use of txt lingo. Secară draws attention to the widespread impact of new social media promoting txt lingo and suggests that audiovisual translation needs to move on with the new context of the new media landscape as also advocated by "the abusive turns" (Nornes, 2007, pp. 176-187). 
The final section, Implication of Web 2.0 for Translation Teaching and Training, addresses the impact of Web 2.0 on translator training on the basis of the author's experience using Facebook in the translation classroom and findings from an awareness survey of professional translators on changing technological environments. Reflecting on his experiences over the past few years using Facebook in the translation classroom Renée Desjardins advocates the merit of social networking platforms, in which contemporary students are increasingly well versed. He maintains that dimensions such as collaboration and peer-reviewing embraced by social networking platforms are increasingly essential to prepare translators-to-be to operate in the pervasive virtual environment. In relation to a more conventional approach using virtual learning environments, Desjardins argues that the benefits of social networking platforms outweigh potential threats such as security issues. His experience in using Facebook leads him to believe that it allows a more wholehearted shift from teacher-centred to learner-centred training, while helping students "navigate the social, academic and professional spheres, physical and virtual, in which they invariably interact". While a cautious approach is required to implement popular social networking platforms in learning environments, it could arguably help ensure that translation students are better informed of the context in which the new forms of social translation practice are developing.

Also seeking questions arising from technological changes in the context of Web 2.0 and beyond Joanna Gough's contribution derives from her 2010 Master's dissertation, which allowed her to survey over 200 translators at varying stages of their profession to reveal their awareness of state-of-the-art technology developments. Her focus was to understand specifically how well practising translators are informed of macro technological trends harnessing openness, sharing and collaborating characteristic of Web 2.0 as well as the more micro context of translation tools that in turn reflect the macro developments. Gough's findings indicate a relatively low awareness of these trends by the respondents, which leads to their lack of uptake, for example, of open tools or engagement in collaborative translation processes. Furthermore, the survey data demonstrate that the deciding factor in translators' awareness of technological changes is the translators' general attitudes towards adopting new technologies. In relation to community translation, the surveyed translators are found to strongly favour a peer-review quality evaluation approach. At the same time, in other related questions concerning crowdsourcing, they are still largely undecided mainly because they have insufficient knowledge on the topic. Gough suggests that the survey findings also indicate that recent graduates are not necessarily wellinformed of the pertinent technological developments and that their main source of technology information was the Internet rather than translation schools, even among relatively recent graduates. Gough sees the need for 
formal translator education to reflect more closely the technological changes, ideally to influence their fundamental attitudes towards technology which is so profoundly affecting the profession. These findings may tie in with the observations by Kelly et al. in this volume for the lack of initiatives by the existing language service providers to integrate an element of community translation. Such evidence indeed calls for an increased awareness of technological developments in academia, especially in translation schools that may tend to consider technology to be a somewhat lesser concern, set aside from the main agenda of translator education.

\section{Future direction of research on community translation}

Community translation is continuously evolving and it is probable that neither professional translators nor scholars in TS are fully informed of all dimensions of the phenomenon. The contributions in this volume begin to locate the emerging practices in the discipline by relating some of the key issues to its concerns. As evident in this volume of Linguistica Antverpiensia New Series - Themes in Translation Studies focused on Community Translation, interest in this domain has already inspired research initiatives in close link with industry partners; the invited contributions by Désilets and van der Meer and Kageura et al. shed light onto the nature of the phenomenon by their significant empirical investigations. Such initiatives will likely contribute to further research interest in TS addressing current issues arising from the wider technological trends. As well as working with industry players who are actually organising and implementing community translation, interaction with practising community participants would also allow translation scholars to gain new theoretical and methodological inspiration. The nature of the topic highlights the increasingly important role of translation technology in translation theory, which has so far failed to make a major epistemic impact (see Jiménez-Crespo). The issues raised in this volume are only the tip of the iceberg, yet they indicate seeds for further avenues of research for readers to take up.

While sharing and collaborating evoke the image of co-operative citizens living convivially together, the translation profession may have sensed the dark side of such trends appearing to somewhat privilege nonprofessionals as dedicated community translators. Technology is often a two-edged sword, bringing both convenience and danger. Translators have benefited greatly from the vast range of multilingual information available on the Internet without which most could not perform their task to satisfaction today. That being the case, one might argue that the new mode of procuring translation via community translation is an inevitable consequence of the free and open Internet harnessing the same spirit which 
has otherwise served translators well. As often implied by the observations made by the contributors in this volume, this new phenomenon provides us with fresh opportunities to reflect on current practices of professional translation, be it its codes of practice, TQA or subtitling norms. Today's translation practices are by no means all ideal. Translators may be given too little time or context to research and translate adequately or may become too norm-driven to experiment with new approaches, thus ignoring the changing face of the various texts and their end use. It is tempting for translation professionals to condemn the emergence of community translation as "the rise of the amateur" but it may actually be pointing to "the crisis of the experts" who "undervalue what they do not know and overvalue what they do" (Gee \& Hayes, 2011, p. 44). While professional translators generally do a wonderful job, it is time to recognise that their operating environments are significantly shifting, giving rise to new ways of working. By being better informed of the nature of the change and by becoming more reflective of current practices, the translation profession will be better served and more likely to survive and flourish in the long run.

\section{Acknowledgements}

I would like to thank all the authors for their contributions and their perseverance through several revision steps. This in turn could not have been possible without the assistance of expert reviewers who went through the articles with fine-toothed combs. Last but not least I would like to express my sincere gratitude to Aline Remael for accommodating this new topic for the journal and both Aline Remael and Iris Schrijver for the ensuing support, including the last intensive stage of editing.

\section{References}

Barry, D. M. (2008). Copy, rip, burn: The politics of copyleft and open source. London: Pluto Press.

Baym, N. (2011). Social Networks 2.0. In M. Consalvo \& C. Ess (Eds), The handbook of Internet studies (pp. 384-405). Malden, MA: Wiley-Blackwell.

Bey, Y., Boitet, C. \& Kageura, K. (2006). The TRANSBey prototype: An online collaborative Wiki-based CAT environment for volunteer translators. In E. Yuste (Ed.), Proceedings of the Third International Workshop on Language Resources for Translation Work, Research \& Training (LR4Trans-III), pp. 4954.

Cronin, M. (2010). The translation crowd. Revista tradumàtica, 8. Retrieved from http://www.fti.uab.cat/tradumatica/revista/num8/articles/04/04.pdf 
DePalma, D. A. \& Kelly, N. (2008). Translation of, by, and for the people. Lowell, Mass: Common Sense Advisory.

Désilets, A. (2007). Translation Wikified: How will massive online collaboration impact the world of translation? ASLIB Translating and the computer 29 Conference Proceedings, London: ASLIB, n.p.

Díaz Cintas, J. \& Muños Sánchez, P. (2007). Fansubs: Audiovisual translation in an amateur environment, The Journal of Specialised Translation, 6, 37-52.

Gee, J. P., \& Hayes, E. (2011). Language and learning in the digital age. London: Routledge.

Howe, J. (2006). The rise of crowdsourcing. Wired 14 (6).

Howe, J. (2008). Crowdsourcing. New York: Random House.

Keegan, N. (2009). Crowdsourcing: Using cross-cultural competency gained from the global proficiency programme to better understand Facebook's Spanish Translation. Retrieved from http://www.bc.edu/offices/international/gp/metaelements/pdf/PDF/2009_Reflection_Projects/Keegan,\%20Nathan.pdf.

Keen, A. (2007). The cult of the amateur. New York: Dubleday.

Kelly, N. (2009). Freelance translators clash with LinkedIn over crowdsourced translation. Retrieved from http://www.commonsenseadvisory.com/ Default.aspx .Contenttype $=$ ArticleDetAD\&tabID=63\&Aid=591\&moduleId=391

Kendall, L. (2011). Community and the Internet. In M. Consalvo \& C. Ess (Eds.), The handbook of Internet studies (pp. 309-325). Malden, MA: Wiley-Blackwell.

Leonard, S. (2005). Progress against the law: Anime and fandom, with the key to the globalization of culture. International Journal of Cultural Studies, 8(3), 281305.

Nornes, M. (2007). Cinema Babel: Translating global cinema. Minneapolis:University of Minesota Press.

OECD (2007). Participative web and user-created content: Web 2.0 wikis and social networking. Paris: OECD Pubishing.

O'Hagan, M. (2009). Evolution of user-generated translation: Fansubs, translation hacking and crowdsourcing. The Journal of Internationalization and Localization, 1(1), 94-121.

Perrino, S. (2009). User-generated translation: The future of translation in a Web 2.0 environment. The Journal of Specialised Translation, 12, http://www.jostrans.org/issue12/artperrino.php.

Pym, A. (2011). Translation research terms: a tentative glossary for moments of perplexity and dispute. In Pym, A (ed.). From Translation Research Projects 3, Tarragona: Intercultural Studies Group, pp. 75-110. http://isg.urv.es/publicity/isg/publications/trp_3_2011/index.htm

Schäler, R. (2008). Localisation. In M. Baker, \& G. Saldanha (Eds.), Routledge encyclopedia of Translation Studies (pp. 157-161). London: Routledge,.

Shirky, C. (2010). Cognitive surplus: Creativity and generosity in a connected age. London: Allen Lane.

Surowiecki, J. (2005). The wisdom of the crowd: Why the many are smarter than the few. London: Abacus. 
Tapscott, D., \& Williams, A. (2006). Wikinomics: How mass collaboration change everything. New York: Portfolio.

Wadensjö, C. (2009). Community interpreting. In M. Baker, \& G. Saldanha (Eds.), Routledge encyclopedia of Translation Studies (pp. 43-48). London: Routledge,.

1 The patent application filed at the US Patent \& Trademark Office is available at: http://appft.uspto.gov/netacgi/nph-Parser?Sect1=PTO2\&Sect2=HITOFF\&p=1\&u=/ netahtml/PTO/search-bool.html\&r=1\&f=G\&l=50\&co1=AND\&d=PG01\&s1= facebook.AS. $\& \mathrm{~s} 2=$ translation. $\mathrm{AB} . \& \mathrm{OS}=\mathrm{AN} /$ facebook+AND+ABST/translation $\& \mathrm{R}$ $\mathrm{S}=\mathrm{AN} /$ facebook $+\mathrm{AND}+\mathrm{ABST} /$ translation 